\title{
Corrosion behaviour of titanium in the presence of Streptococcus mutans
}

\author{
Júlio C.M. Souza ${ }^{a, b, *}$, Pierre Ponthiaux ${ }^{c}$, Mariana Henriques $^{d}$, Rosário Oliveira ${ }^{d}$, \\ Wim Teughels ${ }^{e}$, Jean-Pierre Celis ${ }^{f}$, Luís A. Rocha ${ }^{a}$ \\ ${ }^{a}$ Centre for Mechanical and Materials Technologies, CT2M, Universidade do Minho, P-4800-058 Guimarães, Portugal \\ ${ }^{\mathrm{b}}$ Dental School, School of Health Sciences (FCS), Universidade Fernando Pessoa (UFP), Porto P-4200-250, Portugal \\ ${ }^{\mathrm{c}}$ Ecole Centrale Paris, Chemical Engineering Laboratory (LGPM), F-92290 Châtenay-Malabry, France \\ ${ }^{\mathrm{d}}$ IBB - Institute for Biotechnology and Bioengineering, Universidade do Minho, P-4710-057 Braga, Portugal \\ e Department of Periodontology, KU Leuven, Leuven B-3000, Belgium \\ ${ }^{\mathrm{f}}$ Department of MTM, KU Leuven, Leuven B-3001, Belgium
}

\section{A R T I C L E I N F O}

Article history:

Received 2 January 2013

Received in revised form

19 March 2013

Accepted 26 March 2013

Keywords:

Streptococcus mutans

Biofilm

Fluorides

Titanium

Corrosion

\begin{abstract}
A B S T R A C T
Objective: The main aim of this in vitro study was to evaluate the influence of Streptococcus mutans on the corrosion of titanium.

Methods: S. mutans biofilms were formed on commercially pure titanium (CP-Ti) square samples $(10 \mathrm{~mm} \times 10 \mathrm{~mm} \times 1 \mathrm{~mm})$ using a culture medium enriched with sucrose. Open circuit potential (OCP) and electrochemical impedance spectroscopy (EIS) measurements were used to evaluate the corrosion behaviour of $\mathrm{CP}-\mathrm{Ti}$ in the presence of $\mathrm{S}$. mutans in Fusayama's artificial saliva. The corrosion of biofilm-free CP-Ti samples was also evaluated in artificial saliva. Biofilms biomass was measured by spectrophotometry, using crystal violet staining, after 1, 2 and 7 days.

Results: The OCP values recorded on CP-Ti in the presence of S. mutans $(-0.3 \pm 0.02 \mathrm{~V}$ vs. SCE) was lower than those on biofilm-free CP-Ti $(-0.1 \pm 0.01 \mathrm{~V}$ vs. SCE) after $2 \mathrm{~h}$ of immersion in artificial saliva $(p<0.05)$. That reveals a high reactivity of titanium in presence of $S$. mutans. Impedance spectra revealed the formation of a compact passive film on titanium in artificial saliva or in the presence of a 2 days old S. mutans biofilm even though the corrosion resistance of CP-Ti has decreased in presence of a S. mutans biofilm.

Conclusion: The presence of bacterial colonies, such as S. mutans, negatively affected the corrosion resistance of the titanium.
\end{abstract}

(C) 2013 Elsevier Ltd. All rights reserved.

\section{Introduction}

A biofilm consists of a well-organized community of microbial cells, including one or multi-species agglomerates, surrounded by an extracellular matrix composed of polysaccharides, nucleic acids, $\mathrm{H}_{2} \mathrm{O}$, proteins and other substances. ${ }^{1-3}$ Biofilm accumulation is an important factor that can cause failures of oral rehabilitation systems, especially considering the pathogenic potential of some bacteria such as Streptococcus mutans, Porphyromonas gingivalis and Prevotela intermedia which promote dental caries or periodontal diseases. ${ }^{1-6}$ Since specific types of acid-producing bacteria can promote the degradation of hard

\footnotetext{
* Corresponding author at: Universidade do Minho, Centre for Mechanical and Materials Technologies (CT2M), Departamento de Engenharia Mecânica, Campus Azurém, P-4800-058 Guimarães, Portugal. Tel.: +351 253 510231; fax: +351 253516007.

E-mail addresses: lrocha@dem.uminho.pt, jsouza@dem.uminho.pt (Júlio C.M. Souza). 
tooth structures, restorative materials, such as dental composites or dental amalgam, can also be deteriorated during a biocorrosion process. ${ }^{1,8-13}$ Among the several microorganisms present in the oral cavity, Streptococcus mutans is one of the utmost important due to its capacity to release lactic acid and to grow in acidic environments becoming a powerful corrosive microorganism. ${ }^{1,13-15}$ Moreover, it grows in both aerobic and anaerobic environments, and can be found at different habitats in the oral cavity. ${ }^{1,3}$ In fact, oral biofilms with a high proportion of $S$. mutans cause a $\mathrm{pH}$ decrease in the oral cavity promoting the demineralization of enamel, dentine, and cementum as well as the corrosion of dental restorative materials. ${ }^{1,8-13}$ However, the corrosive role of $\mathrm{S}$. mutans depends on the sucrose concentration present on its environment and in its adhesion to the oral surfaces. ${ }^{1,14-17}$ Although S. mutans is not directly responsible for periodontal inflammations, it is known that oral biofilms consist in consortia of other species depending on environmental conditions like oxygen, nutrients, and $\mathrm{pH}^{1,17-22}$ In addition, the biofilm structure can pick up external acidic substances from dietary, as well as acidic substances produced from microbial metabolism. ${ }^{1,23,31}$

In dentistry, commercially pure titanium is the first choice for dental implants, while titanium alloys (e.g. Ti6Al4V and Ti15Zr4Nb4Ta) are desirable for removable and fixed dental prostheses, due to their good corrosion resistance, low density, high mechanical strength and biocompatibility. ${ }^{24-28}$ Indeed, titanium is a material with a high corrosion resistance compared to other metallic materials used in oral rehabilitation thanks to a compact titanium oxide $\left(\mathrm{TiO}_{2}\right)$ film at its surface in oxygen containing environments. ${ }^{9-12,29-31}$ However, the dissolution of the $\mathrm{TiO}_{2}$ film may occur in certain media such as those containing high fluoride concentrations, hydrogen peroxide $\left(\mathrm{H}_{2} \mathrm{O}_{2}\right)$, and lactic acid, like it can occur in the oral cavity. ${ }^{7,8}$ Moreover, the corrosion of titanium increases when $\mathrm{F}^{-}, \mathrm{H}_{2} \mathrm{O}_{2}$, and lactic acid are combined, as revealed by Mabilleau et al. $^{8}$ Corrosion of titanium results in the release of metallic ions into the surrounding tissues that can stimulate an initial inflammatory response, and a consequent toxic, mutagenic and/or carcinogenic reaction. ${ }^{32,33}$ If severe, the effect of corrosion may be visible in vivo resulting in a change of surface colouration or perimplant inflammations due to the released ions. ${ }^{4,8}$ Guindy et al. $^{7}$ reported the failure of six dental implant systems caused by corrosion of the metallic suprastructure. In that study, areas with clear signs of localized corrosion on implants and inner crown surfaces were detected by light and scanning electron microscopy on all six implants and inner crown surfaces. Corrosion causes a material loss that leads to a dimensional misfit between prosthetic crown and abutment or between abutment and implant. ${ }^{32,33}$

Considering the increased use of titanium in oral rehabilitation, corrosion studies of titanium and its alloys in the presence of microorganisms become very important due to an enormous number of microorganisms and corrosive substances present in the oral cavity which vary from patient to patient and on the oral environmental conditions. The study of the corrosion resistance of titanium in the presence of microorganisms can determine the performance of implantsupported prostheses. As a result, the reduction of restorative material loss by corrosion phenomena can increase the long- term success of dental implant systems. The main goal of this work was to evaluate the influence of S. mutans biofilms typically present in the oral cavity on the corrosion of titanium, through electrochemical techniques.

\section{Materials and methods}

\subsection{Preparation of samples and fluoridated artificial saliva solutions}

Square samples $(10 \mathrm{~mm} \times 10 \mathrm{~mm} \times 1 \mathrm{~mm})$ were cut from sheets of commercially pure titanium (CP-Ti) (VSMPO TIRUS, US, ASTM B 348, Cp-Ti Grade 2). The samples were wet ground on SiC abrasive papers (Struers A/S, Denmark) down to 1200 Mesh. After grinding, samples were first cleaned in isopropyl alcohol (Sigma-Aldrich, USA) for $10 \mathrm{~min}$ and then in distilled water for 5 min using an ultrasonic bath. These samples were stored in a desiccator for 1 day, and sterilized before biofilm formation or electrochemical measurements by autoclaving at $121^{\circ} \mathrm{C}$ for $15 \mathrm{~min}$.

A modified Fusayama's artificial saliva formulation ${ }^{34}$ (Table 1) was used as stock solution in this in vitro corrosion study. The electrochemical behaviour of metallic materials in that solution has been reported to be similar as in human saliva. ${ }^{34}$

\subsection{Bacterial strains and growth conditions}

S. mutans ATCC 25175 were microaerophilically grown for $48 \mathrm{~h}$ at $37^{\circ} \mathrm{C}$ in agar plates with $32 \mathrm{~g} / \mathrm{L}$ of BHI agar (Bacto, Difco, USA) supplemented with $3 \mathrm{~g} / \mathrm{L}$ of yeast extract and $200 \mathrm{~g} / \mathrm{L}$ of sucrose (Bacto, Difco, USA). The bacterial cells were inoculated in Tryptic Soy Broth (TSB, Bacto, Difco, USA) supplemented with $3 \mathrm{~g} / \mathrm{L}$ of yeast extract and $200 \mathrm{~g} / \mathrm{L}$ of sucrose for $18 \mathrm{~h}$ at $37^{\circ} \mathrm{C}$ and $150 \mathrm{rpm}$. After incubation, cells were harvested by centrifugation for $10 \mathrm{~min}$ at $4{ }^{\circ} \mathrm{C}$ and $5000 \mathrm{rpm}$ and washed twice with Phosphate Buffer Solution (PBS, Sigma-Aldrich, USA). Then, the cells were re-suspended in TSB supplemented with mucin $(2.5 \mathrm{~g} / \mathrm{L})$, peptone $(5 \mathrm{~g} / \mathrm{L})$, urea $(1 \mathrm{~g} / \mathrm{L})$, yeast extract $(2 \mathrm{~g} / \mathrm{L})$ and sucrose $(200 \mathrm{~g} / \mathrm{L})$ to obtain an optical density (OD) of about 0.6 at $A_{630}$, corresponding to approximately $1 \times 10^{8} \mathrm{CFU} /$ $\mathrm{ml} .^{5,20-22}$ The OD at $630 \mathrm{~nm}$ was measured using a spectrophotometer (BioTek, USA). This cell suspension was the inoculum for biofilm formation assays.

\subsection{Biofilm formation and analysis}

Titanium samples were placed into 24 well-plates, each containing $2 \mathrm{ml}$ of $\mathrm{S}$. mutans inoculum $\left(1 \times 10^{8} \mathrm{CFU} / \mathrm{ml}\right)$ and

Table 1 - Composition of the stock Fusayama's artificial saliva solution used in this work.

\begin{tabular}{|c|c|}
\hline Compounds & $(g / 1)$ \\
\hline $\mathrm{NaCl}$ & 0.4 \\
\hline $\mathrm{KCl}$ & 0.4 \\
\hline $\mathrm{CaCl}_{2} \cdot 2 \mathrm{H}_{2} \mathrm{O}$ & 0.795 \\
\hline $\mathrm{Na}_{2} \mathrm{~S} \cdot 9 \mathrm{H}_{2} \mathrm{O}$ & 0.005 \\
\hline $\mathrm{NaH}_{2} \mathrm{PO}_{4} \cdot 2 \mathrm{H}_{2} \mathrm{O}$ & 0.69 \\
\hline Urea & 1 \\
\hline
\end{tabular}


incubated at $37^{\circ} \mathrm{C}$. After 24,48 and $168 \mathrm{~h}$ (7 days) of incubation, the samples were transferred for new well-plates and washed twice with PBS for the evaluation of biomass by the crystal violet (CV) staining method. ${ }^{5,30,31}$ Those time points were selected in order to be possible to evaluate the initial phases of biofilm formation immediately after the insertion of titaniumbased abutments or prosthetic frameworks in the oral cavity up to $48 \mathrm{~h}$. The other time point was selected as a longer one in order to evaluate the increase of the biofilm density and $\mathrm{pH}$. The $\mathrm{pH}$ of the culture medium containing S. mutans was measured every day using a pH metre (Mettler Toledo 340, Brazil). Then, the titanium samples were immersed in $1 \mathrm{ml}$ of methanol for $15 \mathrm{~min}$ to allow cell fixation. After that, methanol was removed and the titanium samples were dried at room temperature and $1 \mathrm{ml} \mathrm{CV} \mathrm{(1 \% )} \mathrm{was} \mathrm{added} \mathrm{to} \mathrm{stain} \mathrm{the} \mathrm{bacterial}$ biofilm for $5 \mathrm{~min}$. After that, the titanium samples were dipwashed in distilled water, dried at room temperature, and transferred to new 24-well plates containing $1 \mathrm{ml}$ of acetic acid (33\%) in order to remove the CV solution from cells. The suspension was aspirated (aliquots of $200 \mu \mathrm{l}$ ) and placed in 96well plates to determine the OD at $540 \mathrm{~nm}$.

For microscopic analyses, surfaces covered with biofilms were washed two times in PBS and fixed in glutaraldehyde $2 \%$ for $5 \mathrm{~min}$. Then surfaces were washed three times in PBS, and dehydrated through a series of graded ethanol solutions (50, $70,80,90,100 \%)$. Samples covered with S. mutans biofilms were sputter-coated with gold, and analyzed by Scanning Electron
Microscopy (SEM, S360 LEICA CAMBRIDGE) at $15 \mathrm{kV}$ and by Field-Emission Scanning Electron Microscopy (FESEM, FEI QUANTA $400 \mathrm{FEG}$ ) at 5-10 kV at an angle of $60^{\circ}$.

\subsection{Corrosion measurements}

Samples covered or not with S. mutans biofilms were mounted in an acrylic electrochemical cell connected to the external electrical wiring. The electrochemical tests were carried out with a Voltalab PGZ100 potentiostat (Radiometer Analytical) coupled to the Voltamaster 4 software used for electrochemical control and data analyses. The open circuit potential (OCP) is defined as the potential of an electron conductive material immersed in an ion conductive electrolyte and measured against a reference electrode. In this work, a standard calomel reference electrode (SCE, Radiometer Analytical, XR110 model) was used. A Pt-electrode (Radiometer Analytical, M231PT model) was used as counter electrode in impedance and potentiodynamic polarization tests. The test samples were connected as working electrode. Since on immersion of a test sample in the Fusayama's artificial saliva, the OCP evolves with time, a waiting time was inserted till the OCP stabilized. The titanium test samples covered with biofilms were tested in Fusayama's artificial saliva solution A group of titanium samples without biofilms used as control group, was immersed in sterilized growth medium for $48 \mathrm{~h}$ before their OCP was measured in Fusayama's solution.
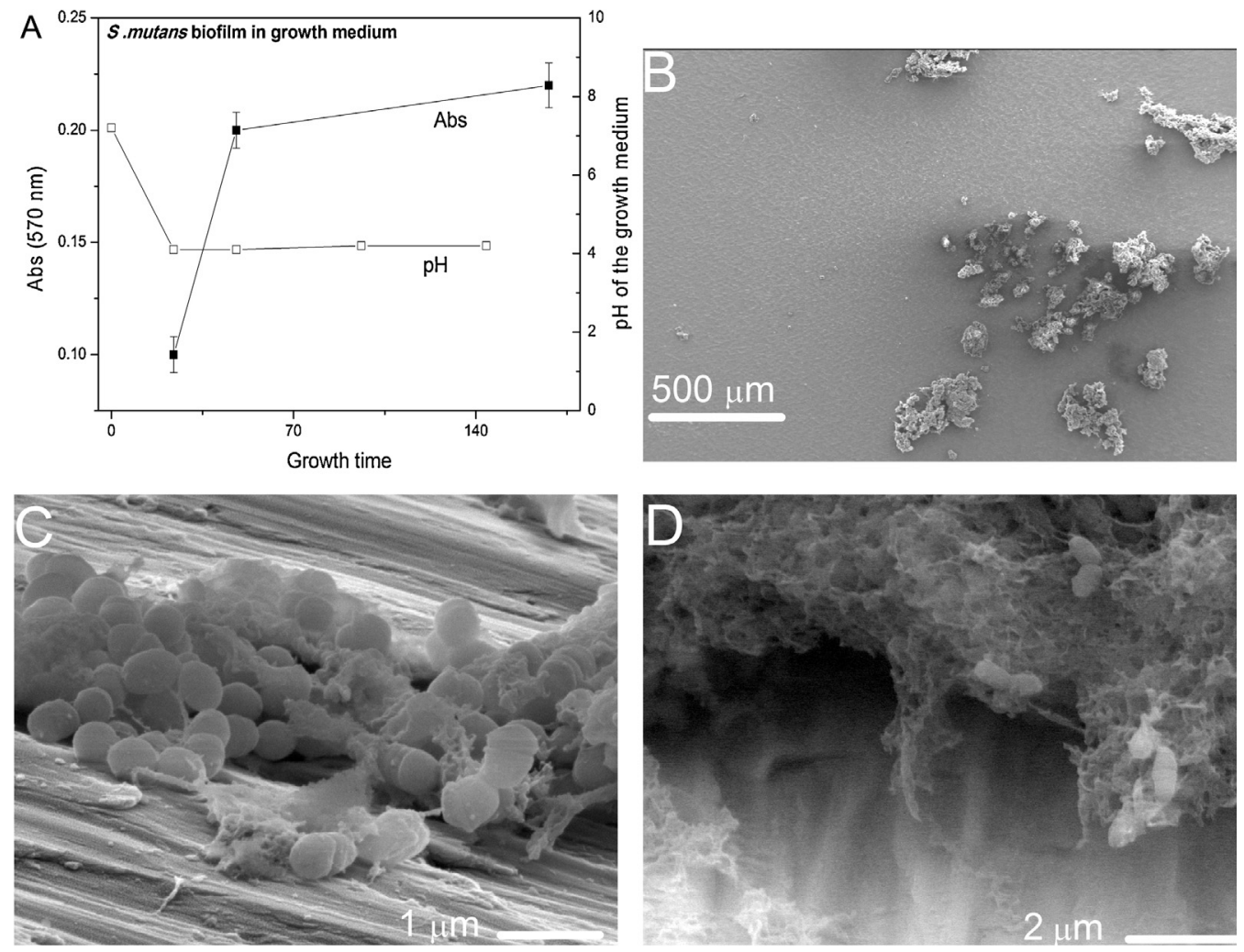

Fig. 1 - Crystal violet absorbance (Abs) of S. mutans biofilm biomass formed on titanium surfaces and pH of biofilm medium after 24, 48, and $168 \mathrm{~h}$ (7 days) of growth (growth in TSBMPY20\%S, $37{ }^{\circ} \mathrm{C}, 150 \mathrm{rpm}$ ). Images of S. mutans biofilms formed (grown in TSBMPY20\%S, $37{ }^{\circ} \mathrm{C}, 150 \mathrm{rpm}$ ) on titanium surfaces after (C) 24, and (B and D) $48 \mathrm{~h}$. Images obtained by FEGSEM operated in secondary electrons (SE) mode at $10 \mathrm{kV}$ and an angle of $60^{\circ}$. 


\subsection{Statistical analysis}

The results were statistically analyzed via one-way analysis of variance (ANOVA), at a significance level of $p<0.05$ by using the SPSS 17.0 software for Windows (Chicago, IL, USA).

\section{Results}

\subsection{Biofilm analysis}

The biomass of S. mutans biofilms formed on titanium samples was determined after 24, 48, and $168 \mathrm{~h}$ by absorbance measurements after CV staining (Fig. 1). A significant increase $(p<0.05)$ of biomass occurs after $48 \mathrm{~h}$ of incubation. However, no statistically significant differences $(p<0.05)$ were found between the biomass present after 48 and $168 \mathrm{~h}$ (7 days) of incubation. Also, as shown in Fig. 1A, the $\mathrm{pH}$ of the growth medium becomes acidic ( $\mathrm{pH}$ ca. 4) during the growth of the biofilm. The morphology of $S$. mutans biofilms formed on titanium surfaces is shown in Fig. 1B-D. A higher biofilm accumulation is noticed after $48 \mathrm{~h}$ of growth than after $24 \mathrm{~h}$. Additionally, a higher production of extracellular polysaccharides and the existence of canals below and inside a biofilm grown for $48 \mathrm{~h}$, are observed (Fig. 1). SEM images did not reveal the presence of a localized corrosion on the titanium surfaces after a biofilm growth for $48 \mathrm{~h}$.

\subsection{Corrosion measurements in artificial saliva solutions} in the presence of $\mathrm{S}$. mutans biofilms

A decrease of the OCP was recorded on titanium covered with S. mutans biofilms grown for $48 \mathrm{~h}$ as shown in Fig. 2. After an immersion for 2 days in a sterile growth medium, the OCP values recorded on titanium samples without biofilms evolve towards more noble values (0 V vs. SCE) in artificial saliva.

Also, EIS tests were performed for $48 \mathrm{~h}$ to evaluate the state of the titanium passive film in the presence of biofilms (Fig. 3A). The EIS spectra (Fig. 3A) for titanium surfaces free of biofilms reveal values of the phase angle approach from $-90^{\circ}$ and a higher inclination of the slopes ([Z] vs. Frequency) than

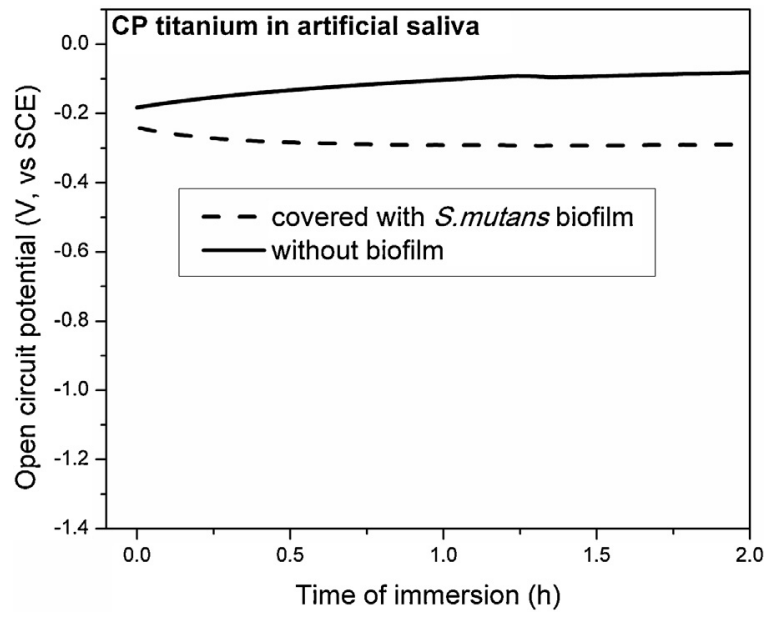

Fig. 2 - Evolution of open circuit potential (OCP) recorded on titanium covered or not with $\mathrm{S}$. mutans biofilms grown during $48 \mathrm{~h}$ in TSBMPY20\%S (37 $\left.{ }^{\circ} \mathrm{C}, 150 \mathrm{rpm}\right)$, and immersed in Fusayama's artificial saliva.

those recorded on titanium covered with $S$. mutans. That indicates higher values of the total impedance for titanium without biofilms than in presence of biofilms $(p<0.05)$.

An equivalent circuit was derived from non-linear square fitting of EIS spectra, as shown in Fig. 3B. That circuit known as Randle's circuit consists of a passive film capacitance $\left(C_{f}\right)$ in parallel with a polarization resistance of the passive film $\left(R p_{f}\right)$ in series with a solution resistance $\left(R_{s}\right)$. Randle's circuit indicates a capacitive behaviour of titanium surface in presence of a compact titanium oxide film in both cases (Fig. 3B). In other words, there was no formation of defects such as pits on the titanium surfaces with and without biofilms.

The values of $R p_{f}$ and $C_{f}$ obtained by fitting of EIS spectra are shown in Fig. 4. The equivalent electrical circuits as well as experimental and theoretical values showed an adequate fitting in agreement to chi-square values $\left(\chi^{2}\right)$ between $10^{-4}$ and $10^{-5}$. After analyzes of $C_{f}$ and $R p_{f}$ values by ANOVA, significant

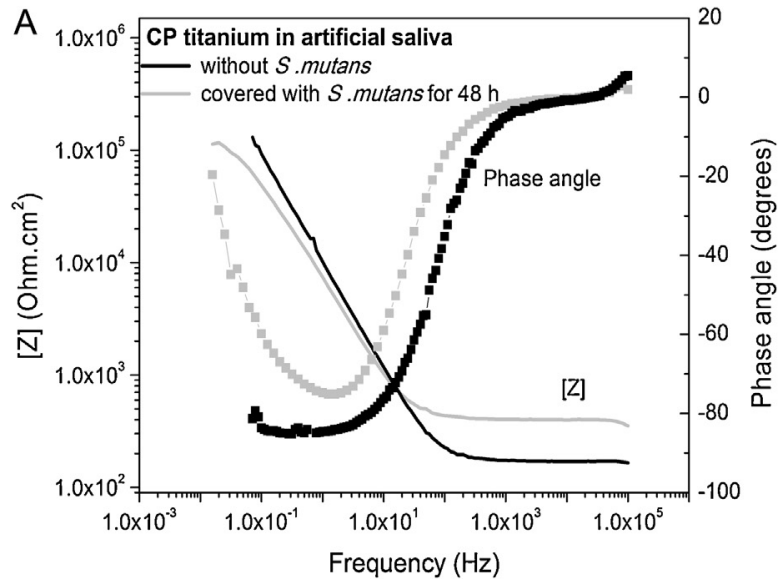

B $\quad \mathrm{TiO}_{2}$ compact film

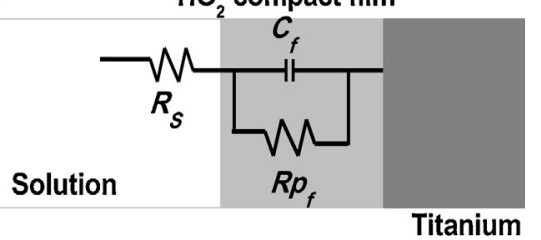

Fig. 3 - (A) EIS spectra (bode representation) for titanium covered or not with S. mutans biofilms (48 h of growth in TSBMPY20\%S, $37^{\circ} \mathrm{C}, 150 \mathrm{rpm}$ ) and (B) the corresponding electrical circuit. 

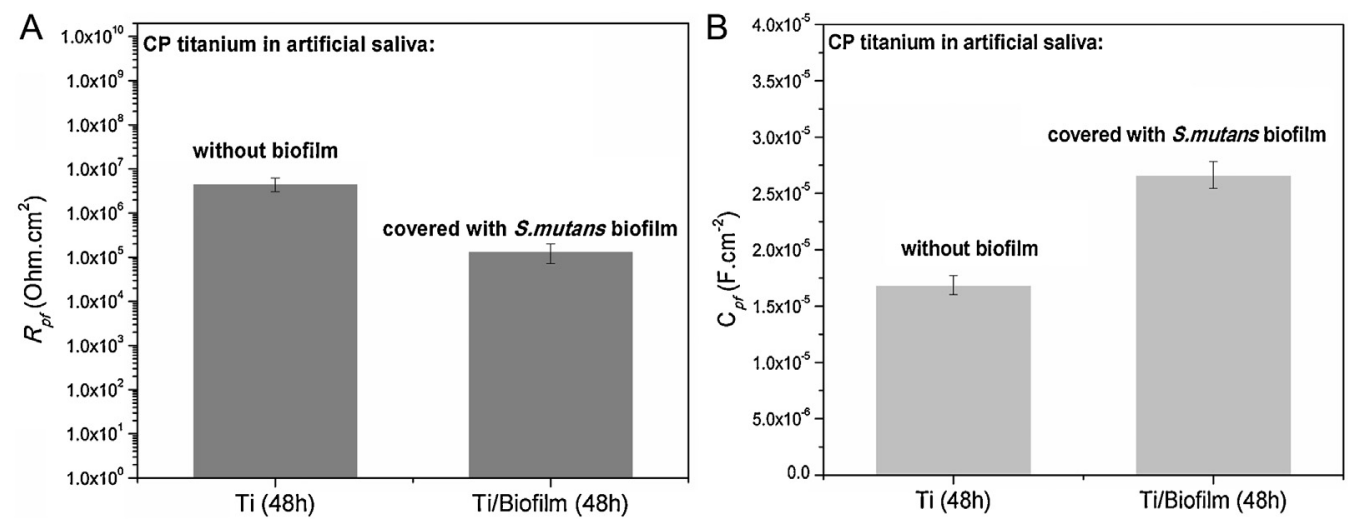

Fig. 4 - (A) Polarization resistance $\left(R p_{f}\right)$ and $(B)$ capacitance of titanium passive film $\left(C_{f}\right)$ with and without $S$. mutans biofilms grown for $48 \mathrm{~h}$ in TSBMPY20\%S $\left(37^{\circ} \mathrm{C}, 150 \mathrm{rpm}\right)$ when immersed in artificial saliva.

differences $(p<0.05)$ were found between the two groups of titanium samples. The lowest values of $R p_{f}$ (Fig. 4A) were observed for titanium covered with biofilms what confirms the decreased corrosion resistance in presence of $S$. mutans. As shown in Fig. $4 \mathrm{~B}$, the values of $C_{f}$ for titanium without biofilms are lower than those for titanium covered with biofilms, although in both cases the impedance results indicate the presence of a passive film. Additionally, these values of $C_{f}$ suggest a higher thickness of the $\mathrm{TiO}_{2}$-film in absence of biofilms compared to titanium covered with biofilms.

\section{Discussion}

In this work, the corrosive effect S. mutans on titanium was evaluated by electrochemical techniques associated to biofilm density and microscopic analyses. S. mutans agglomerates surrounded by their extracellular matrix could be detected on titanium over a period of $48 \mathrm{~h}$ of growth (Fig. 1). Considering that S. mutans agglomeration, the colonization of different kinds of surfaces and materials by $S$. mutans has been investigated in previous studies. ${ }^{1,6-8} \mathrm{~S}$. mutans has been classified as hydrophobic performing its initial adhesion on titanium surfaces supported by glycoprotein as e.g., mucin or polysaccharides extracellular matrix. ${ }^{1,16-18}$ Electrostatic interactions on the adsorption of mucin to titanium as well as between mucin and $S$. mutans, are responsible for the initial

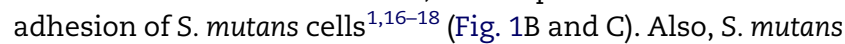
growth can be enhanced by high sucrose concentration, so that the production of extracellular matrix leads to biofilm agglomeration $^{1,16-19}$ (Fig. 1D). The stabilization of biofilm growth noticed after $48 \mathrm{~h}$, Fig. 1A, instead of an increase, could be explained by a detachment of some parts of the biofilm biomass to the surrounding environment, which is a characteristic of mature biofilms. ${ }^{1,17,21}$

Even though the growth conditions used in this study allowed the agglomeration of S. mutans on titanium surface at high density, it was not detected a localized corrosion of titanium in the presence of S. mutans over a period of $48 \mathrm{~h}$ of growth. Nevertheless, the decrease of OCP noticed during electrochemical tests indicated an increase of the chemical reactivity of titanium or else a higher corrosion susceptibility of titanium in the presence of biofilms.

Impedance tests confirmed the OCP results indicating a decrease of the corrosion resistance in presence of $S$. mutans (Fig. 4). The amount of electric charge stored on the titanium surface (in an electric field) immersed in an electrolyte is represented by $C_{f .}{ }^{10}$ The dielectric properties of the passive film can be estimated from the equivalent electrical circuit once an increase of capacitance results in a decrease of the dielectric properties of the passive film. On the other side, $R p_{f}$ indicates the ability of the passive film to resist of a current flow on its surface, or else the corrosion resistance of the passive film. ${ }^{10}$ The decreased corrosion resistance can be due to the release of lactic acid from S. mutans metabolism at high sucrose concentrations to the surrounding environment ${ }^{1}$ as shown by $\mathrm{pH}$ measurements (Fig. 1A). Also, formic and acetic acids can be released from $S$. mutans metabolism at low sucrose concentration during prolonged periods without nutrients ${ }^{1}$ what can contribute to a decrease of $\mathrm{pH}$ in the surrounding. The presence of acidic substances, produced by S. mutans, on titanium could significantly decrease the $\mathrm{pH}$ of the growth medium (Fig. 1A). Thus, the continuous decrease of $\mathrm{pH}$ might corrode titanium surfaces located below and around the biofilms. Also, a higher decrease of the corrosion resistance of titanium can be noticed in the presence of mixed biofilms than in the presence of mono-species biofilms.

Considering that the $\mathrm{pH}$ of the growth medium was at 4 in presence of high density biofilms, one may assume that the $\mathrm{pH}$ within the biofilm could be much lower than the one resulting from a gradual diffusion of acidic substances through the biofilm biomass up to titanium surface.

As reported in previous studies, ${ }^{9-12}$ the dissolution rate of the titanium oxide film at low $\mathrm{pH}$ is associated to the $\mathrm{H}^{+}$ concentration in the solution. That results in the formation of hydrated $\mathrm{Ti}$ oxides as $\mathrm{Ti}(\mathrm{OH})_{3}{ }^{+}$, and further in a release of Tiions and $\mathrm{TiO}_{2}$ ultra-fine particles to the surrounding environment. Titanium ions might prevent or decrease bacterial growth due to their toxicity on bacterial cells. In fact, a high concentration of $\mathrm{Ti}$ particles at $500 \mathrm{ppm}$ can decrease the microbial cell viability. ${ }^{1}$ However, Ti ions and $\mathrm{TiO}_{2}$ ultra-fine 
particles (diameter up to $100 \mathrm{~nm}$ ) have been reported as toxic for human cells. ${ }^{32,33}$ In addition, the release of $\mathrm{Ti}$ ions and particles results in a material loss that can promotes failures in titanium-based structures of dental prostheses and implant connections.

\section{Conclusions}

Concerning the presence of biofilms, the growth of S. mutans onto titanium surfaces stabilizes after 2 days of incubation in an enriched medium with a high sucrose concentration. Titanium surfaces covered with a biofilm grown for 2 days, exhibited a capacitive behaviour revealing the presence of a compact titanium passive film without the occurrence of localized corrosion when immersed in artificial saliva. However, the presence of S. mutans colonies on the titanium surface negatively affected the corrosion resistance as revealed by the polarization resistance of the titanium passive film. In fact, the decrease of $\mathrm{pH}$ caused by acidic substances released from $S$. mutans metabolism can induce the corrosion of titanium-based frameworks and implant-abutment joints during a prolonged period at high sucrose concentration, or in association with other acidic substances and fluorides in the oral cavity.

\section{Acknowledgements}

The authors acknowledge the financial support provided by Alban Programme (cod. E06D103407BR), the Erasmus Student Exchange Programme of the CEC, FCT (PTDC/CTM/67500/2006) and the Scientific Research Community on Surface Modification of Materials funded by the Flemish Science Foundation (WOG-FWO-Vlaanderen).

\section{R E F E R E N C E S}

1. Marsh P, Martin M. Oral microbiology. 5th ed. Edinburgh: Churchill Livingstone Elsevier; 2009.

2. Costerton JW, Stewart PS, Greenberg EP. Bacterial biofilms: a common cause of persistent infections. Science 1999;284:1318-22.

3. Broggini N, Mcmanus LM, Hermann JS, Medina RU, Oates TW, Schenk RK, Buser D, Mellonig JT, Cochran DL. Persistent acute inflammation at the implant-abutment interface. Journal of Dental Research 2003;82(3):232-7.

4. Rosentritt M, Hahnel S, Gröger G, Mühlfriedel B, Bürgers. Handel G. Adhesion of Streptococcus mutans to various dental materials in a laminar flow chamber system. Journal of Biomedical Materials Reseach Part B Applied Biomaterials 2008;86B:36-44.

5. Lobo M, Gonçalves RB, Ambrosano GM, Pimenta LA. Chemical or microbiological models of secondary caries development around different dental restorative materials. Journal of Biomedical Materials Research 2005;74B:725-31.

6. Barbour ME, O'Sullivan DJ, Jenkinson HF, Jagger DC. The effects of polishing methods on surface morphology, roughness and bacterial colonisation of titanium abutments. Journal of Materials Science: Materials in Medicine 2007;18(7):1439-47.
7. Guindy JS, Schiel H, Schmidli F, Wirz J. Corrosion at the marginal gap of implant-supported suprastructures and implant failure. International Journal of Oral \& Maxillofacial Implants 2004;19:826-31.

8. Mabilleau G, Bourdon S, Joly-Guillou ML, Filmon R, Baslé MF, Chappard D. Influence of fluoride, hydrogen peroxide and lactic acid on the corrosion resistance of commercially pure titanium. Acta Biomaterialia 2006;2:121-9.

9. Marino CEB, Mascaro LE. EIS characterization of a Ti-dental implant in artificial saliva media: dissolution process of the oxide barrier. Journal of Electroanalytical Chemistry 2004;568:115-20.

10. Shreir LL, Jarman RA, Burstein GT. Corrosion Corrosion Control, 3rd ed., vol. 2. Butterworth/Heinemann; 2000. 1478 pp.

11. Hanawa T, Asami K, Asaoka K. Repassivation of titanium and surface oxide film regenerated in simulated bioliquid. Journal of Biomedical Materials Research 1998;40:530-8.

12. Ibris N, Mirza Rosca JC. EIS study of Ti and its alloys in biological media. Journal of Electronalytical Chemistry 2002;526:53-62.

13. Beyth N, Bahir R, Matalon S, Domb AJ, Weiss EI. Streptococcus mutans biofilm changes surface-topography of resin composites. Dental Materials 2008;24(6):732-6.

14. Ge J, Catt DM, Gregory RL. Streptococcus mutans $\alpha$-enolase binds salivary mucin MG2 and human plasminogen. Infection and Immunity 2004;72:6748-52.

15. Li Y, Burne RA. Regulation of the gtfBC and $\mathrm{ftf}$ genes of Streptococcus mutans in biofilms in response to $\mathrm{pH}$ and carbohydrate. Microbiology 2001;147:2841-8.

16. Toda Y, Moro I, Kogai T, Asakawai H, Hamadai S. Ultrastructure of extracellular polysaccharides produced by serotype c Streptococcus mutans. Journal of Dental Research 1987;66(8):1364-9.

17. Lori JA, Nok AJ. Mechanism of adsorption of mucin to titanium in vitro. Biomedical Materials Engineering 2004;14(4):557-63.

18. Rickard AH, Gilbert P, High NJ, Kolenbrander PE, Handley PS. Bacterial coaggregation: an integral process in the development of multi-species biofilms. Trends in Microbiology 2003;11:94-100.

19. Guggenheim B, Giertsen E, Schupbach P, Shapiro S. Validation of an in vitro biofilm model of supragingival plaque. Journal of Dental Research 2001;80(1):363-70.

20. Sissons $\mathrm{CH}$, Wong L, Shu M. Factors affecting the resting $\mathrm{pH}$ of in vitro human microcosm dental plaque and Streptococcus mutans biofilms. Archives of Oral Biology 1998;43:93-102.

21. Teughels W, Van Assche N, Sliepen I, Quirynen M. Effect of material characteristics and/or surface topography on biofilm development. Clinical Oral Implant Research 2006;17:68-81.

22. Montanaro L, Campoccia D, Rizzi S, Donati ME, Breschi L, Prati C, Arciola CR. Evaluation of bacterial adhesion of Streptococcus mutans on dental restorative materials. Biomaterials 2004;25:4457-63.

23. Watson PS, Pontefract HA, Devine DA, Shore RC, Nattress BR, Kirkham J, Robinson C. Penetration of fluoride into natural plaque biofilms. Journal of Dental Research 2005;84(5):451-5.

24. Niinomi M. Recent research and development in titanium alloys for biomedical applications and healthcare goods. Science and Technology of Advanced Materials 2003;4: 445-54.

25. Anusavice KJ. Dental materials. 11 ed. Elsevier; 2003.

26. Misch CE. Dental implant prosthetics. St. Louis: Mosby; 2005

27. Kerber SJ. Bioreactivity of titanium implant alloys. Journal of Vacuum Science \& Technology A 1995;13(5):2619-23. 
28. Cai Z, Shafer T, Watanable I, Nunn ME, Okabe T. Electrochemical characterization of cast titanium alloys. Biomaterials 2003;24:213-8.

29. Blackwood DJ, Peter LM, Williams DE. Stability and open circuit breakdown of the passive oxide film on titanium. Electrochemical Acta 1998;33(8):1143-9.

30. Souza JC, Henriques M, Oliveira R, Teughels W, Celis JP, Rocha LA. Do oral biofilms influence the wear and corrosion behavior of titanium? Biofouling 2010;26(4):471-8.

31. Souza JC, Henriques M, Oliveira R, Teughels W, Rocha LA, Celis JP. Biofilms inducing ultra-low friction on titanium. Journal of Dental Research 2010;89(12):1470-5.
32. Wang JJ, Sanderson BJS, Wang H. Cyto- and genotoxicity of ultrafine $\mathrm{TiO}_{2}$ particles in cultured human lymphoblastoid cells. Mutation Research 2007;628:99-106.

33. Urban RM, Jacobs JJ, Tomlinson MJ, Gavrilovic J, Black J, Peoc'h M. Dissemination of wear particles to the liver, spleen, and abdominal lymph nodes of patients with hip or knee replacement. Journal of Bone \& Joint Surgery 2000;82:45776.

34. Fusayama T, Katayori $\mathrm{T}$, Nomoto S. Corrosion of gold and amalgam placed in contact with each other. Journal of Dental Research 1963;42:1183-97. 